\title{
Absorção de água pelas raízes do limoeiro sob distintas freqüências de irrigação'
}

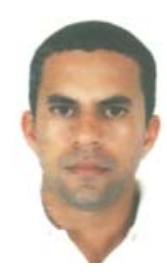

\author{
Delfran B. dos Santos ${ }^{2}$, Eugênio F. Coelho ${ }^{3}$ \& Carlos A. V. de Azevedo
}

1 Parte da Dissertação de Mestrado do primeiro autor, apresentada na UFCG

2 DEA/UFV, CEP 36571-000, Viçosa, MG. Fone: (31) 3899-1939. E-mail: delfran@universiabrasil.net (Foto)

${ }^{3}$ Embrapa Mandioca e Fruticultura. Rua Embrapa s/n, CP 007, CEP 44380-000, Cruz das Almas, BA. Fone: (75) $3621-8021$. E-mail: ecoelho@cnpmf.embrapa.br

${ }^{4}$ DEAg/CCT/UFCG, Av. Aprígio Veloso 882, Bodocongó, Bloco CM, $1^{\circ}$ andar, CP 10078, CEP 58109-970, Campina Grande, PB. Fone: (83) 310-1056, Fax (83) 310-1185. E-mail: cazevedo@deag.ufcg.edu.br

Protocolo 111 - 27/5/2003 - Aprovado em 30/3/2005

\begin{abstract}
Resumo: objetivou-se, nesse trabalho, caracterizar a absorção de água pelas raízes do limoeiro 'Taiti' (Citrus latifolia Tanaka) no perfil de solo sob diferentes intervalos de irrigação por microaspersão. O estudo foi realizado em condições semi-áridas, em solo franco arenoso, cuja absorção de água pelas raízes das plantas foi determinada a partir da umidade em diversas posições no perfil do solo entre duas irrigações, por meio de sondas de TDR. A distribuição radicular foi avaliada a partir de dados de comprimento e diâmetro das raízes nas mesmas posições das sondas de TDR. Conforme os resultados, verificou-se que: (i) à medida que as raízes se afastam do microaspersor, a extração de água pelas raízes do limoeiro é reduzida; (ii) o limoeiro extrai mais água do solo quando não há restrição de disponibilidade hídrica; (iii) sempre que os intervalos entre as irrigações aumentam, cresce também a área de extração de água pelo sistema radicular do limoeiro; (iv) as raízes das plantas com diâmetros entre 0,5-2 mm foram as que mais extraíram água do solo.
\end{abstract}

Palavras-chave: microaspersão, sistema radicular, lima ácida Taiti

\section{Water uptake by lemon roots under different irrigation frequencies}

\begin{abstract}
The present work had the objective of characterizing water uptake by 'Taiti' lemon (Citrus latifolia Tanaka) roots in the soil profile under different microsprinkler irrigation intervals. The work was conducted under semi-arid conditions, in a sandy loam soil. Water uptake by roots was determined from soil water content by means of TDR probes, at several positions in the soil profile between two irrigation events. The root distribution was evaluated based upon data of length and root diameter at the same locations of TDR probes. According to the results, it was verified that: (i) water uptake reduced as the distance root-microsprinkler increased; (ii) lemon crop extracts more water when there is no restriction to the available water in the wetted volume; (iii) the area of water uptake by lemon roots increases with increase in the irrigation intervals; (iv) roots with diameter between 0.5 and $2.0 \mathrm{~mm}$ extracted more water from the soil.
\end{abstract}

Key words: microsprinkler, root system, lemon Taiti

\section{INTRODUÇÃO}

A demanda crescente pelos recursos hídricos acentua cada vez mais a necessidade de manejo criterioso e racional, de modo a assegurar a integridade, a produtividade, a diversidade e a vitalidade dos sistemas aquáticos e de suas bacias hidrográficas (Bucks, 1995). A irrigação localizada apresenta- se como uma alternativa ao atendimento dessas necessidades, em virtude de proporcionar maior eficiência na aplicação de água, além de permitir a aplicação simultânea de fertilizantes, reduzindo custos e aumentando a eficiência de produção.

O sistema radicular das culturas desempenha importante papel nos estudos das interações que ocorrem entre o solo, as plantas e os organismos vivos, uma vez que o conhecimento da 
sua distribuição permite o uso mais adequado de práticas de cultivo, tais como manejo e fertilização do solo, além de se constituir em requisito para elaboração de projetos e execução do manejo de irrigação (Coelho et al., 2001).

Os estudos sobre distribuição de raízes envolvendo a absorção de água pelas plantas, têm sido apresentados na literatura mas, em geral, pouco freqüentes para fruteiras (Coelho \& Or, 1996; Coelho \& Or, 1998). Em plantas frutíferas encontramse alguns trabalhos avaliando a absorção de água pelas raízes do mamoeiro (Silva et al., 2001; Coelho et al., 2002) e da bananeira (Costa et al., 2002).

A absorção de água pelas raízes das plantas sob irrigação, nem sempre tem sido considerada no manejo da irrigação; entretanto, pode constituir-se, juntamente com o conhecimento da distribuição radicular, numa expressiva ferramenta para tomada de decisão no uso de sistemas de irrigação localizada e no manejo da agricultura irrigada.

O conhecimento das zonas de absorção de água pelo sistema radicular, em maior ou menor intensidade, auxilia na instalação e posicionamento dos sensores de água do solo (Machado \& Coelho, 2000), além de definir a área na superfície do solo onde deve ser feita a adubação de modo que o fertilizante aplicado seja eficientemente utilizado pela cultura.

Ante o exposto, tornam-se necessárias informações técnicocientíficas, principalmente no que diz respeito à caracterização das regiões do perfil do solo onde ocorre maior absorção de água pelas raízes das plantas. Assim sendo, com o presente trabalho teve-se por objetivo caracterizar a absorção de água pelas raízes do limoeiro "Taiti”, no perfil de solo sob diferentes intervalos de irrigação por microaspersão.

\section{MATERIAL E MÉTODOS}

O trabalho foi realizado na fazenda Boa Vista, pertencente à empresa Iaçu Agropastoril Ltda, localizada no município de Iaçu, BA, na região semi-árida, localizada geograficamente pelas coordenadas: latitude de $12^{\circ} 34^{\prime}$ Sul e longitude de $40^{\circ} 01^{\prime}$ Oeste do meridiano de Greenwich. A área experimental foi plantada com limão 'Tahiti', enxertado sobre o porta-enxerto Citrumelo 'Swingle', com cinco anos de idade, em espaçamento de $4 \times 7 \mathrm{~m}$ e irrigada por microaspersão. O clima, segundo a classificação de Köppen, é do tipo BSwh (clima quente de caatinga), com chuvas de verão e períodos áridos bem definidos no inverno. Os dados de precipitação diária e evapotranspiração potencial de Penman modificado - FAO 24 (Doorenbos \& Pruitt, 1977) foram coletados por meio de uma estação agrometeorológica automática, instalada próximo da área experimental. Os dados do experimento foram coletados no período de 24/9/2001 a 20/10/2001. O solo da área é um
Latossolo Amarelo distrófico típico, de textura média, com topografia plana, cujas características físico-hídricas se apresentam na Tabela 1.

O experimento foi desenvolvido para avaliar as freqüências de irrigação de um, dois e três dias, aplicando-se a lâmina de água correspondente à reposição de $100 \%$ da evapotranspiração potencial. As avaliações foram realizadas em três plantas (uma planta para cada freqüência de irrigação), sendo que, para cada planta, foram instaladas duas baterias de sensores de umidade do solo, ou sondas de TDR (Reflectometria no domínio do tempo), sendo uma bateria na posição ortogonal à fileira de plantas e outra bateria longitudinal à fileira. Cada bateria de sensores foi instalada obedecendo-se à configuração de uma malha com a seguinte disposição no perfil longitudinal à fileira de plantas: 0,$15 ; 0,25 ; 0,50 ; 0,75 ; 1,0 ; 1,5 \mathrm{e}$ $2,0 \mathrm{~m}$ de distância horizontal da planta e 0,$15 ; 0,25 ; 0,50 ; 0,75$; 1,0 e $1,2 \mathrm{~m}$ de profundidade no perfil do solo. No sentido ortogonal à fileira de plantas, utilizaram-se as mesmas posições, com acréscimo da posição horizontal à fileira de plantas de 2,5 m.

$\mathrm{O}$ teor de água no perfil do solo foi monitorado via sondas de TDR, no período de 24/9/2001 a 5/10/2001, para as três freqüências de um, dois e três dias. As leituras de umidade foram realizadas duas vezes ao dia, uma imediatamente antes de se iniciar a irrigação e outra uma hora após cessar a irrigação, para dois ciclos de irrigação. A diferença entre as umidades em cada posição amostrada depois de uma irrigação e antes do próximo fornecimento de água, permitiu que fosse calculada a extração de água pelas raízes no respectivo período de tempo, conforme a Eq. (1) apresentada em Coelho \& Or (1997),

$$
\mathrm{ESR}=\theta \mathrm{d}-\theta \mathrm{a}
$$

donde,

ESR - extração de água do solo pelas raízes, $\mathrm{m}^{3} \mathrm{~m}^{-3}$

$\theta d$ - umidade do solo uma hora depois da irrigação, $\mathrm{m}^{3} \mathrm{~m}^{-3}$

$\theta \mathrm{a}$ - umidade do solo imediatamente antes da irrigação subseqüente, $\mathrm{m}^{3} \mathrm{~m}^{-3}$

Admitiu-se que a diferença entre as umidades após cada irrigação e antes da irrigação seguinte, refere-se à extração da água pelas raízes da planta, uma vez que a evaporação de água do solo foi eliminada pela cobertura da superfície do solo e pela alta eficiência de aplicação do sistema de irrigação por microaspersão, o que restringe o efeito da percolação. Para se avaliar se houve perda por percolação, a umidade foi monitorada a profundidade de 1,2 $\mathrm{m}$ do perfil do solo, em várias distâncias do emissor.

Tabela 1. Atributos físico-hídricos do solo da área experimental

\begin{tabular}{|c|c|c|c|c|c|c|c|}
\hline \multirow{3}{*}{$\begin{array}{l}\text { Profundidade } \\
\qquad(\mathrm{m})\end{array}$} & & & & \multicolumn{2}{|l|}{ Porosidade } & \multicolumn{2}{|c|}{ Umidade } \\
\hline & Areia Total & Silte & Argila & \multirow{2}{*}{$\begin{array}{l}\text { Total } \\
(\%)\end{array}$} & \multirow{2}{*}{$\begin{array}{l}\text { Densidade } \\
\left(\mathrm{g} \mathrm{cm}^{-3}\right)\end{array}$} & $6 \mathrm{kPa}$ & $1500 \mathrm{kPa}$ \\
\hline & & $\mathrm{g} \mathrm{kg}^{-1}$ & & & & \multicolumn{2}{|c|}{$\mathrm{m}^{3} \mathrm{~m}^{-3}$} \\
\hline 0,25 & 771,0 & 92,0 & 137,0 & 0,41 & 1,46 & 0,157 & 0,078 \\
\hline 0,50 & 643,0 & 129,0 & 228,0 & 0,42 & 1,48 & 0,169 & 0,100 \\
\hline 0,75 & 593,0 & 145,0 & 262,0 & 0,40 & 1,52 & 0,214 & 0,126 \\
\hline 1,00 & 583,0 & 126,0 & 291,0 & 0,41 & 1,45 & 0,216 & 0,114 \\
\hline
\end{tabular}


As percentagens de água disponível no perfil foram determinadas com base na curva característica de água do solo para cada profundidade, empregando-se a Eq. (2):

$$
\mathrm{AD}^{\prime}=\left(\frac{\theta-\theta \mathrm{pmp}}{\theta \mathrm{cc}-\theta \mathrm{pmp}}\right) * 100
$$

donde,

$$
\begin{aligned}
& \mathrm{AD} \text { - percentagem de água disponível no perfil do solo, \% } \\
& \theta \text { - umidade do solo, } \mathrm{m}^{3} \mathrm{~m}^{-3} \\
& \theta \mathrm{pmp} \text { - ponto de murcha permanente, } \mathrm{m}^{3} \mathrm{~m}^{-3} \\
& \theta c c \quad \text { - água disponível do solo, } \mathrm{m}^{3} \mathrm{~m}^{-3}
\end{aligned}
$$

Com auxílio do software Surfer 7.0, foram elaborados os gráficos das isolinhas de extração de água do solo pelas raízes e das isolinhas referentes às percentagens de água disponível do perfil do solo.

A coleta de amostras de solo-raíz se deu nas mesmas posições onde estavam inseridas as sondas de TDR. Foram abertas duas trincheiras por planta, uma no sentido ortogonal à fileira de plantas e outra no sentido longitudinal, com duas plantas (repetições) por freqüência. As amostras foram coletadas a partir de blocos de solo de $0,10 \times 0,10 \times 0,05 \mathrm{~m}$, pelo método dos monólitos (Bohm, 1979).

Após coletadas da trincheira, as amostras foram codificadas e levadas para o laboratório, onde as raízes foram separadas do solo por lavagem com água. Uma vez individualizadas, as raízes foram levadas a um "scanner" de resolução de 600 dpi escala $100 \%$ e brilho entre 135 e 165, conforme os diâmetros (Kaspar \& Ewing, 1997; Coelho et al., 1999) onde foram digitalizadas em arquivos TIFF - "Targed Image File Format". Os arquivos TIFF foram posteriormente submetidos ao software Rootedge (Kaspar \& Ewing, 1997) para a determinação da área, comprimento e diâmetro de raízes.

\section{RESULTADOS E DISCUSSÃO}

Não ocorreu perda de água por percolação, conforme observado, a 1,2 $\mathrm{m}$ de profundidade do perfil do solo (Figura 1), em que a umidade variou de 0,04 a $0,12 \mathrm{~m}^{3} \mathrm{~m}^{-3}$, visto que ela corresponde ao ponto de murcha permanente, de $0,11 \mathrm{~m}^{3} \mathrm{~m}^{-3}$.

Na Figura 2A e B vê-se que, no sentido longitudinal, a extração de água do solo pelo sistema radicular (ESR) localizouse a distâncias horizontais da planta inferiores a $1,5 \mathrm{~m} \mathrm{e}$ profundidade até $0,5 \mathrm{~m}$. Para distâncias horizontais da planta, inferiores a $0,5 \mathrm{~m}$, a ESR foi constatada a profundidade de 1,1 $\mathrm{m}$. No perfil ortogonal, a ESR se localizou na região de profundidade de 0 a $0,5 \mathrm{~m}$ e na distância horizontal da planta de 0 - $1,2 \mathrm{~m}$.

Pelos resultados apresentados observa-se que, quanto maior a distância do microaspersor, menor é a atividade do sistema radicular. Esta redução se deve à diminuição de água disponível no perfil do solo (Figura $2 \mathrm{C}$ e D), em função do raio de alcance do microaspersor. Nas maiores distâncias, as lâminas que caem na superfície do solo são insuficientes para infiltrar e aumentar suficientemente o teor de água do solo. Com base nisso é possível identificar o volume do solo onde a extração de água pelas raízes é mais significativa.
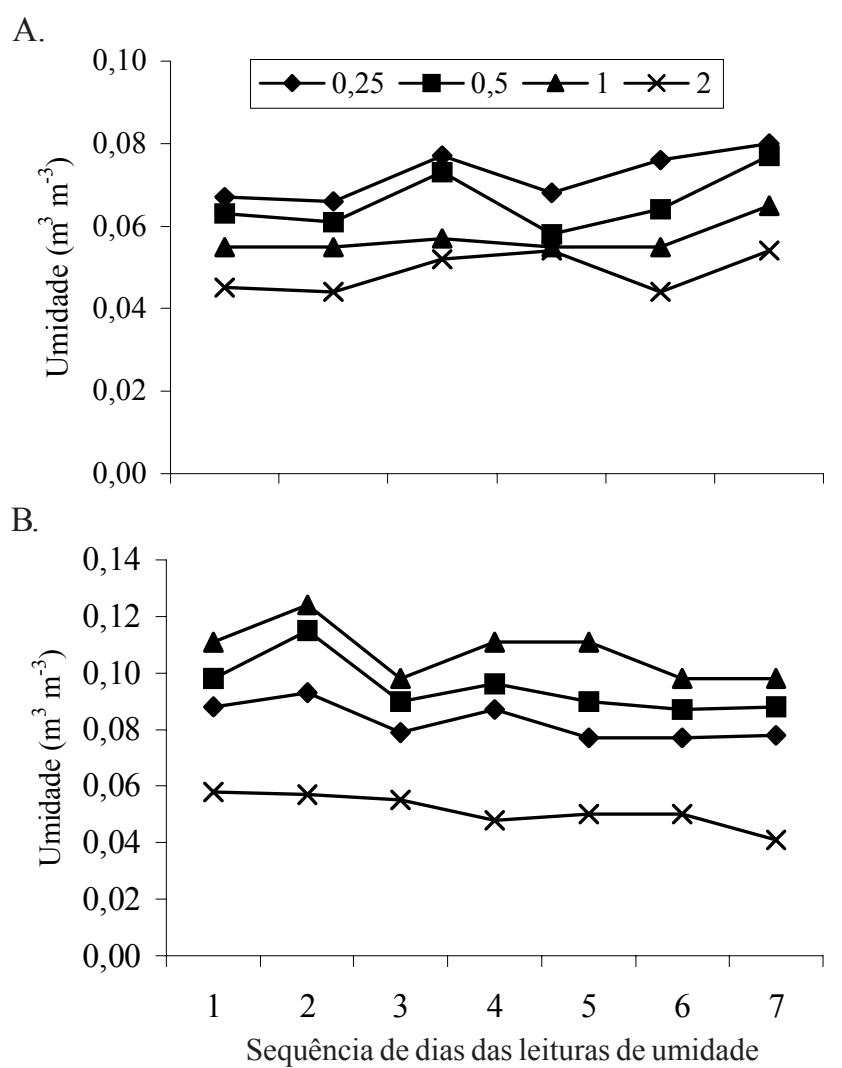

Figura 1. Variação do teor de umidade no perfil do solo na profundidade de $1,2 \mathrm{~m}$ nas posições de 0,$25 ; 0,5 ; 1,0$ e $1,2 \mathrm{~m}$ de distância horizontal em relação à planta, nos perfis longitudinal (A) e ortogonal (B) à fileira de plantas

Conforme evidenciado na Figura 2, o limoeiro extrai mais água do perfil quando não há restrição da disponibilidade no solo, isto é, $100 \%$ da água disponível. Na proporção em que a disponibilidade é reduzida, o volume extraído pelas raízes também diminui, até que não haja mais extração. A extração é reduzida a zero quando não há disponibilidade de água no solo. Esta situação atual do solo de $0,11 \mathrm{~m}^{3} \mathrm{~m}^{-3}$, correspondente ao estado de potencial total caracterizado como ponto de murcha permanente.

Informações dessa natureza podem ser úteis ao manejo de irrigação, não só no que se refere à antecipação do conhecimento de quando e de quanto de água aplicar mas, também, para definir zonas para melhor monitoramento de água do solo, por sensores de potencial matricial ou de umidade (Machado \& Coelho, 2000). O conhecimento da área onde ocorre a maior atividade do sistema radicular da cultura, exerce importante utilidade no estudo de distribuição de nutrientes via solo, uma vez que a absorção de água e de nutrientes ocorre simultaneamente, assim como a determinação do local mais indicado para coleta de amostras destinadas à avaliação da fertilidade sob irrigação localizada.

Nas áreas de maior atividade radicular, registraram-se as maiores variações de água do perfil, em função do tempo, de onde a água é extraída para suprir a evapotranspiração da cultura. Essas informações estão compatíveis com as apresentadas por Coelho \& Or (1999) após constatarem que a maior variação de umidade ocorre nas posições de maior atividade das raízes, que coincide com regiões do volume 
A.

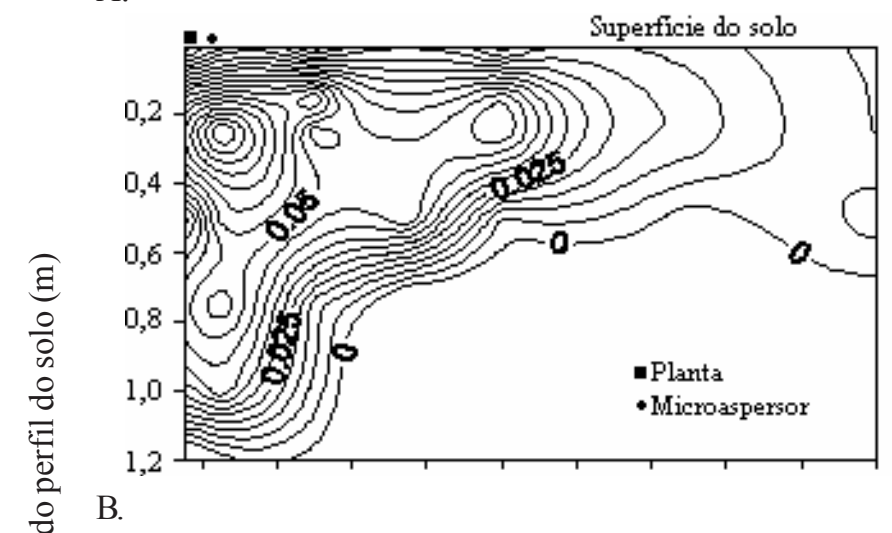

C.

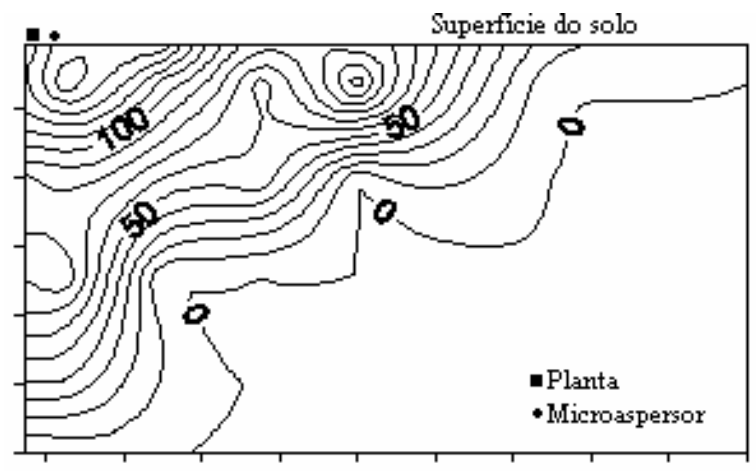

D.

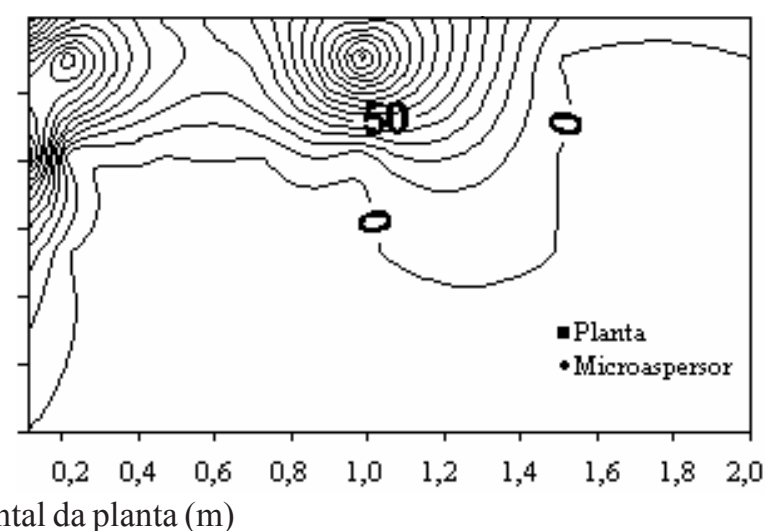

Figura 2. Isolinhas referentes à extração de água do solo pelas raízes das plantas - ESR, $\left(\mathrm{m}^{3} \mathrm{~m}^{-3}\right)$, nas direções longitudinal (A) e ortogonal (B) à fileira de plantas e do teor de água disponível em percentagem, nas direções longitudinal (C) e ortogonal (D) à fileira de plantas

molhado. Conforme os autores, nesses ambientes estão as mais altas oscilações no potencial matricial nas posições mais próximas do emissor, devido à influência da extração de água pelas raízes.

Conforme sugerido por Santos (2002) a partir do conhecimento da área de maior atividade das raízes, onde a extração de água é mais acentuada, pode-se caracterizar a profundidade efetiva de extração (PEe) e a distância efetiva de extração (DEe) de água do solo, pelo sistema radicular.

Santos (2002) estabeleceu que a profundidade efetiva de extração (PEe) de água do solo pelo sistema radicular, seja a área do perfil do solo a partir da superfície na qual se encontram pelo menos $80 \%$ do total de extração de água pelas raízes e que a distância efetiva de extração (DEe) de água do solo pelo sistema radicular seria a região do perfil do solo a partir do pé da planta onde se encontram pelo menos $80 \%$ do total de extração de água pelas raízes da cultura.

De acordo com a Figura 3, observa-se que, para a freqüência de irrigação de um dia, a DEe alcançou $0,39 \mathrm{~m}$ da planta e a PEe atingiu $0,5 \mathrm{~m}$ (Figura $3 \mathrm{~A}$ ); para a freqüência de dois dias, a DEe alcançou distâncias até $0,45 \mathrm{~m}$ da planta e a PEe atingiu a profundidade de $0,52 \mathrm{~m}$ (Figura $3 \mathrm{~B}$ ) e, na freqüência de três dias, a DEe alcançou até $0,75 \mathrm{~m}$ da planta e a PEe atingiu até 0,48 m (Figura 3C).

Machado \& Coelho (2000) estimaram a profundidade efetiva das raízes de lima ácida 'Tahiti', através do método de variação do conteúdo de água no solo e encontraram uma PEe de $0,4 \mathrm{~m}$, resultado esse próximo aos abordados nessa pesquisa.
A partir dos resultados (Figura 3) percebeu-se que, com o aumento do intervalo de irrigação, a área de extração de água do perfil do solo pelo sistema radicular do limoeiro aumentou, o que pode ser atribuído ao também aumento da disponibilidade de água depois da irrigação.

A Figura 4 ilustra a distribuição das percentagens do comprimento total de raízes, por classe de diâmetro, referentes aos perfis ortogonal e longitudinal. No sentido longitudinal, as maiores percentagens de raízes finas $(0,5-2,0 \mathrm{~mm}) \mathrm{se}$ encontraram na profundidade de 0 a $0,2 \mathrm{~m}$ e distâncias horizontais do tronco de até $2 \mathrm{~m}$.

As raízes de diâmetro entre 2 e $5 \mathrm{~mm}$, localizaram-se mais freqüentemente na profundidade de 0 a $0,20 \mathrm{~m}$ e na distância horizontal da planta inferior a 1,6 m. As raízes entre 5 e $10 \mathrm{~mm}$ foram encontradas na profundidade de 0 a $0,4 \mathrm{~m}$, a distâncias horizontais da planta inferiores a $0,3 \mathrm{~m}$. No perfil ortogonal, as raízes finas $(0,5-2 \mathrm{~mm})$ estavam presentes até a profundidade de $0,2 \mathrm{~m}$ para distância horizontal inferior a $1,5 \mathrm{~m}$. As raízes de diâmetro entre 2 e $5 \mathrm{~mm}$ se concentraram até $0,8 \mathrm{~m}$ de profundidade e a uma distância horizontal da planta entre $0,4 \mathrm{e}$ $1 \mathrm{~m}$. As raízes de maior diâmetro $(5-10 \mathrm{~mm})$ tenderam a se concentrar a distâncias horizontais inferiores a $0,8 \mathrm{~m}$ da planta.

A Figura 5 mostra que quase $85 \%$ do total de raízes se encontraram na profundidade de $0,25 \mathrm{~m}$ e cerca de $80 \%$ à distância horizontal inferior a $1 \mathrm{~m}$ do caule da planta. A partir de $0,75 \mathrm{~m}$ de profundidade, as raízes foram reduzidas, 
A.

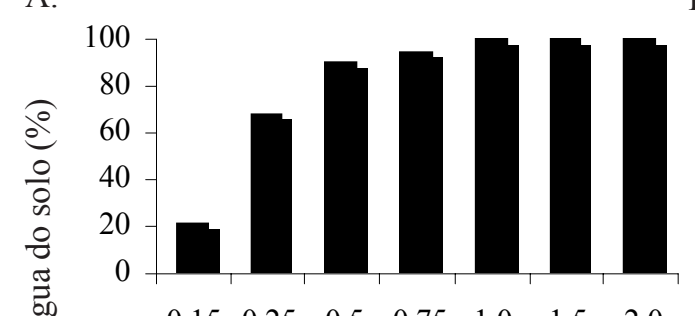

$\begin{array}{lllllll}0,15 & 0,25 & 0,5 & 0,75 & 1,0 & 1,5 & 2,0\end{array}$
B.

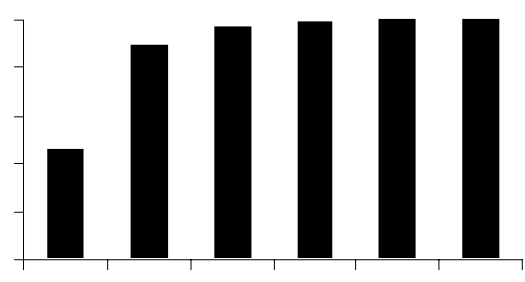

$\begin{array}{llllll}0,25 & 0,5 & 0,75 & 1,0 & 1,5 & 2,0\end{array}$

Distância horizontal do tronco $(\mathrm{m})$
C.

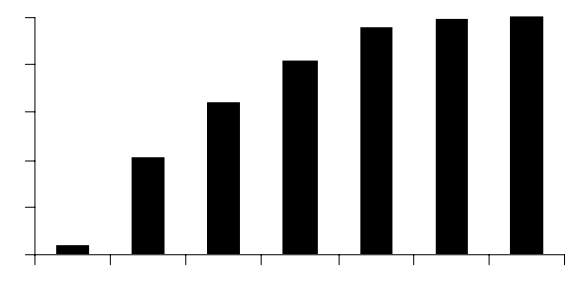

$\begin{array}{lllllll}0,15 & 0,25 & 0,5 & 0,75 & 1,0 & 1,5 & 2,0\end{array}$
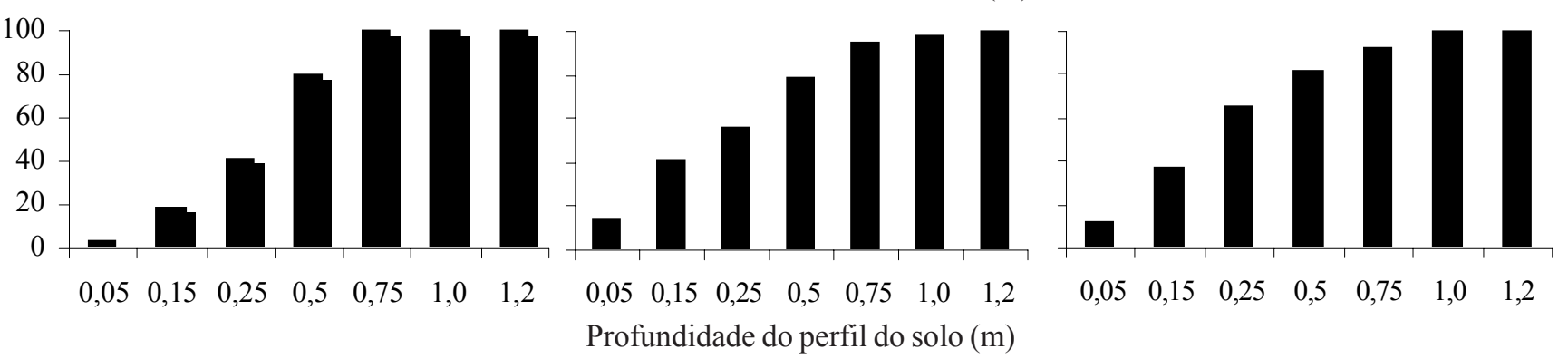

Figura 3. Extração total de água pelo sistema radicular do limoeiro, nos intervalos de irrigação de um dia (A), dois dias (B) e três dias $(\mathrm{C})$ e nas distâncias horizontal da planta e vertical, do perfil do solo

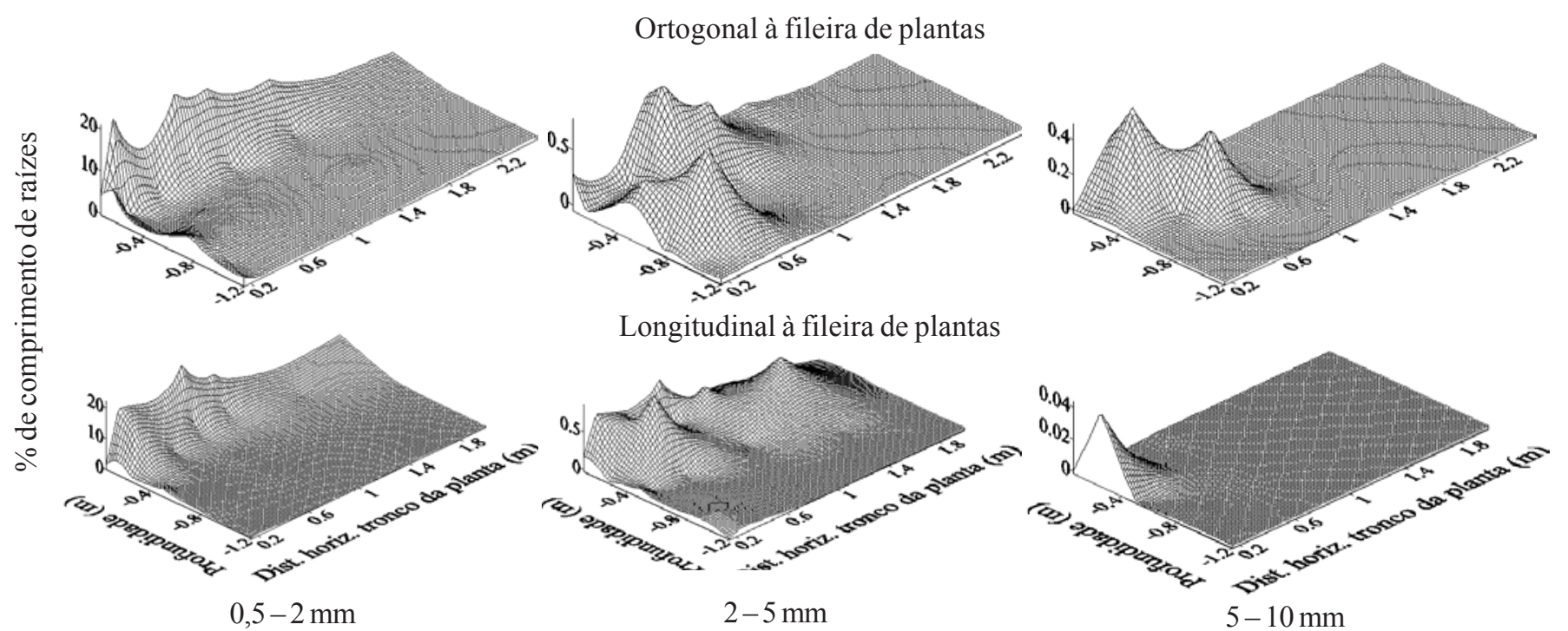

Figura 4. Percentagem de comprimento de raízes de diferentes diâmetros relativo ao comprimento total de raízes em dois perfis (ortogonal e longitudinal à fileira de plantas), estando a planta na posição $(0,0,0)$

notadamente para valores próximos de $5 \%$ e a distância de 1,5 $\mathrm{m}$ para 3,5\% e, no maior intervalo de irrigação, ou seja, três dias, o percentual foi reduzido para $10 \%$.

Neves et al. (2004) estudando a distribuição de raízes em seis porta-enxertos cítricos em um Latossolo Vermelho distroférrico, verificaram que $80 \%$ das raízes se localizaram entre 31 e $53 \mathrm{~cm}$ na linha de plantio e $68 \mathrm{~cm}$ na entrelinha, sendo que a distância na entrelinha ultrapassou o raio da copa das árvores para P. trifoliata, tangerina 'Sunki', limões 'Volcameriano' e 'Rugoso da África'. Esses resultados estão ligeiramente superiores aos encontrados nesta pesquisa, significando que o sistema radicular das plantas cítricas é muito dinâmico e varia de acordo com o tipo de solo, sistema de irrigação, variedade e idade das plantas (Zhang et al., 1996; Oliveira et al., 1998; Carvalho et al., 1999).
A diminuição das raízes a $1,5 \mathrm{~m}$ de distância horizontal da planta e $0,75 \mathrm{~m}$ de profundidade (Figura 5), pode ser atribuída à queda no percentual da água disponível no perfil do solo, resultado que reforça a afirmação de que a distribuição de água no solo constitui uma variável determinante na distribuição de raízes no solo sob irrigação localizada, o que concorda com Clausnitzer \& Hopmans (1994), Clothier \& Green (1994) e Coelho et al. (2002).

Ao se analisar as Figuras 4 e 5, conjuntamente, verifica-se que as maiores concentrações de raízes se situam na parte superficial do solo de $0-0,25 \mathrm{~m}$ e, nessa mesma região, se encontram as maiores concentrações de raízes com diâmetros de 0,5-2 $\mathrm{mm}$, inferindo que esta classe de raízes foi a maior responsável pela extração de água do solo. Coelho et al. (2002) avaliando a distribuição de raízes de laranja "Pêra" sob irrigação 
A.
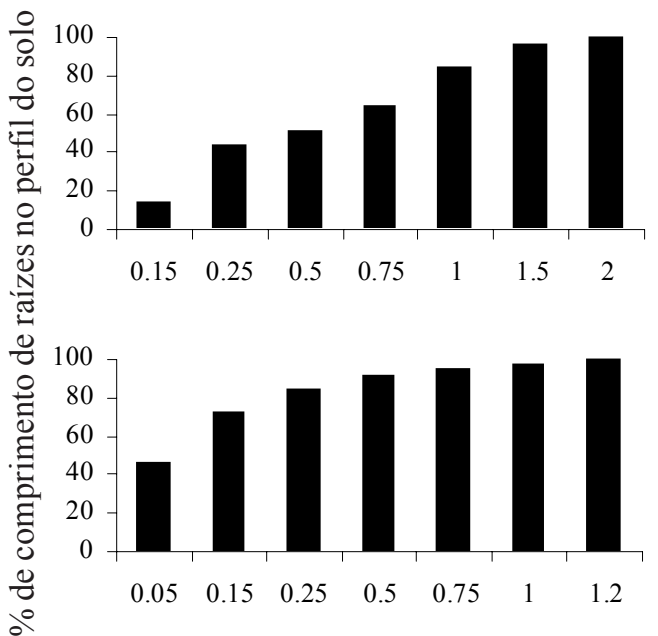

B.

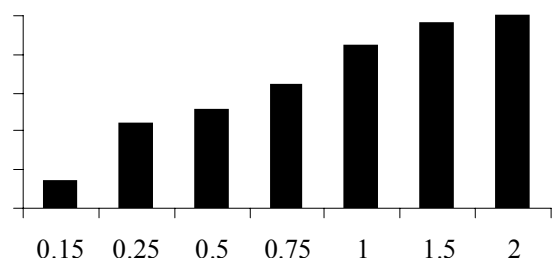

Distância horizontal da planta (m)

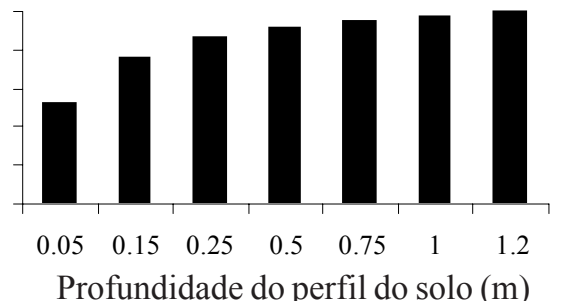

C.
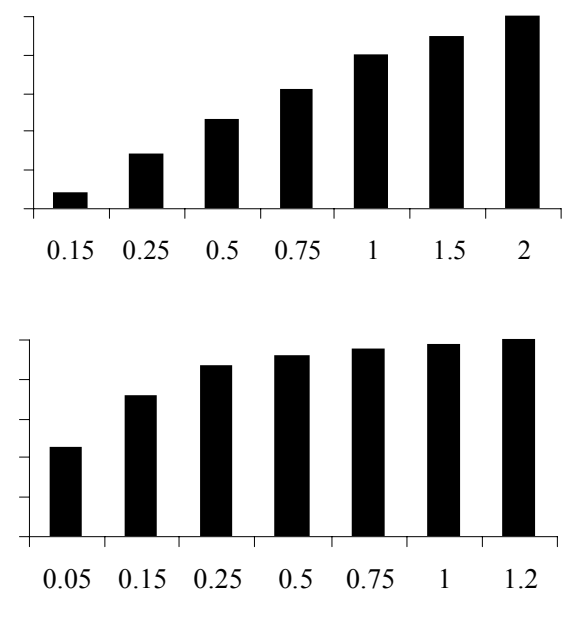

Figura 5. Distribuição de raízes do citrumelo 'Swingle' sob lima ácida 'Tahiti', referente aos intervalos de irrigação de um dia (A), dois dias (B) e três dias (C) em relação à distância horizontal da planta e da profundidade do perfil do solo

por microaspersão, concluíram que as classes de raízes finas e muito finas, se encontram em maior incidência no solo.

A partir dos resultados, constata-se que a distribuição do sistema radicular funciona como alternativa para auxiliar no planejamento da irrigação mas, isoladamente não fornece informações suficientes para um manejo eficiente da mesma; percebe-se, então, que há necessidade, também, de avaliações sistemáticas sobre o perfil de umidade ao longo do solo, de vez que, considerando-se apenas o sistema radicular, estar-se-ia subestimando a profundidade do perfil do solo para aplicação da lâmina bruta de água de irrigação e superestimando a área em relação à distância da planta para instalação de sensores de umidade e aplicação de fertilizantes.

Pelo exposto, nota-se que, para adotar um planejamento eficiente do uso de água via irrigação em função da distribuição das raízes no solo, faz-se necessário observar a área efetiva de extração de água pelas raízes.

\section{CONCLUSÕES}

1. A atividade do sistema radicular do limoeiro diminui na medida em que se afasta do microaspersor.

2. O limoeiro extrai mais água do solo quando não há restrição de disponibilidade hídrica.

3. O aumento no intervalo entre as irrigações resultou no crescimento da área de extração de água do solo, pelo sistema radicular do limoeiro.

4. A classe de raízes com diâmetros entre $0,5-2 \mathrm{~mm}$ proporcionou maior extração de água do solo.

\section{LITERATURA CITADA}

Bohm, W. Methods of studyng root systems. New York: Springer Verlag, 1979. 190p.

Bucks, D.A. Historical devlopment in microirrigation. In: International Microirrigation Congress, 5., 1995, Orlando, Proccedings... St.Joseph: 1995. p.1-5.
Carvalho, J.E.B.; Souza, L.S.; Jorge, L.A.C.; Ramos, W.; Costa Neto, A.O.; Araújo, A.M.A.; Lopes, L.; Jesus, M. Manejo de coberturas do solo e sua interferência no desenvolvimento do sistema radicular da laranja 'Pêra'. Revista Brasileira de Fruticultura, Jaboticabal, v.21, n.2, p.140$145,1999$.

Clausnitzer, V.; Hopmans, J.W. Simultaneous modeling of transient three-dimensional root growth and soil water flow. Plant and Soil, Dordrecht, v.164, n.2, p.299-314, 1994.

Clothier, B.E.; Green, S.R. Root zone processes and the efficient use of irrigation water. Agricultural Water Management, Amsterdam, v.25, n.1, p.1-12, 1994.

Coelho, E.F.; Oliveira, F.C.; Araújo, E.C.E.; Vasconcelos, L.F.L. Distribuição de raízes de laranja "Pêra" sob sequeiro e irrigação por microaspersão em solo arenoso. Pesquisa Agropecuária Brasileira. Brasília, v.37, n.5, p.603-611, 2002.

Coelho, E.F.; Oliveira, F.C.; Araujo, E.C.E.; Vasconcelos, L.F.L.; Lima, D.M. Distribuição do sistema radicular da mangueira sob irrigação localizada em solo arenoso de tabuleiros costeiros. Revista Brasileira de Fruticultura, Jaboticabal, v.23, n.2, p.250-256, 2001.

Coelho, E.F.; Oliveira, F.C.; Vasconcelos, L.F.L.; Araújo, E.C.E. Comparação dos métodos de obtenção de imagens digitais de raízes. In: Congresso Brasileiro de Engenharia Agrícola, 28., 1999, Pelotas. Anais... Pelotas: SBEA/UFPEL-FEA, 1999. CD-ROM

Coelho, E.F.; Or, D. A parametric model for two-dimensional water uptake by corn roots under drip irrigation Soil Science Society of America Journal, Madison, v.60, n.4, p.1039-1049, 1996.

Coelho, E.F.; Or, D. Applicability of analiytical solutions for flow from point sources to drip irrigation management. Soil Science Society of America Journal. Madison, v.61, n.5, p.1331-1341, 1997.

Coelho, E.F.; Or, D. Root distribution and water uptake patterns of corn under surface and subsurface drip irrigation. Plant and Soil, Dordrecht, v.206, n.2, p.123-136, 1998. 
Coelho, E.F.; Or, D. Modelo de distribuição de água e de potencial matricial no solo sob gotejamento com extração de água por raízes. Pesquisa Agropecuária Brasileira. Brasília, v.34, n.2, p.225-234, 1999.

Coelho, E.F.; Silveira, L.N.; Lima, D.M.; Queiróz, J.S. Absorção de água pelas raízes do mamoeiro sob três freqüências de irrigação por gotejamento In: Congresso Nacional de Irrigação e Drenagem, 12, 2002, Uberlândia: ABID, CD Rom

Costa, E.L.; Coelho, E.F.; Silva, T.S.M.; Lima, D.M. Absorção de água pela cultura da bananeira Prata Anã nas condições do Recôncavo Baiano e Norte de Minas In: Congresso Brasileiro de Engenharia Agrícola, 31, 2002, Salvador: SBEA, 2002, CD Rom

Doorenbos, J.; Pruit, W. O. Crop water requirements. Rome: FAO 1977, 179p. Irrigation and drainage, Paper n.24

Kaspar, T.C.; Ewing, R.P. Rootedge: software for measuring root length from desktop scanner images. Agronomy Journal, Madison, v.89, p.932-940. 1997.

Machado, C.C.; Coelho, R.D. Estudo da distribuição espacial do sistema radicular do limão "Cravo" enxertado com lima ácida “Tahiti”. Laranja, Cordeirópolis, v.21, n.2, p.359-380, 2000.
Neves, C.S.V.J.; Murata, I.M.; Stenzel, N.M.C.; Medina, C. de C.; Borges, A.V.; Okumoto, S.H.; Lee, R.H.C.; Kanai, H.T. Distribuição do sistema radicular de porta-enxertos para lima ácida 'Tahiti'. Scientia Agrícola, Piracicaba, v.61, n.1, p.9499, 2004.

Oliveira, F.C.H.; Vieira, D.B.; Souza, I.F.; Oliveira, L.F.C.; Sousa, I.S. Estudo do sistema radicular da tangerineira 'Cleopatra' com copa de laranjeira 'Pêra'. Laranja, Cordeirópolis, v.19, n.1,p.117-131, 1998.

Santos, D.B. Extração de água pelo limão 'Tahiti' com porta enxerto Citrumelo 'Swingle' sob microaspersão nas condições semi-áridas da Bahia. Campina Grande: UFPB. 2002, 112p. Dissertação Mestrado

Silva, T.S.M.; Coelho, E.F.; Lima, D.M.; Santos, D.B. Absorção de água pelo sistema radicular do mamoeiro irrigado por diferentes sistemas de microirrigação. In: Congresso Nacional de Irrigação e Drenagem, 2001, 11, Fortaleza: ABID, 2001.p.6-11.

Zhang, M.; Alva, A.K.; Li, Y.C.; Calvert, D.V. Root distribution of grapefruit trees under dry granular broadcast vs. fertirrigation method. Plant and Soil, Dordrecht, v.183, n.1, p. 79-84, 1996. 